Report No. DOE/

\title{
ROCK MATRIX AND FRACTURE ANALYSIS OR FLOW IN WESTERN TIGHT GAS SANDS
}

DOE/MC/21179--T5

Quarterly Technical Progress Report

DE92 017655

January-March, 1985

N.R. Morrow

K.R. Brower

J.S. Ward

\begin{abstract}
New Mexico Petroleum Recovery Research Center
New Mexico Institute of Mining and Technnlogy Socorro, New Mexico
\end{abstract}

Contributors:

Shlrleen Bretz

Vijaya Dandge

Mary Graham

Ingrid Klich

PRRC Report 85-13

Prepared for the Department of Energy Under Contract No. DE-A.C21-84MC.2.1179

NOTICE

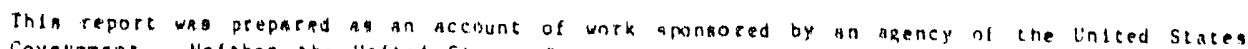
Goveltrente. Nelther the Unlied Stated Goverwmenc nor any apency theteof, nor any of thels enoloyees, makes any watancy, expreas or tmplled, op asoutles any lepal llabllity or reaponsiblitty for the accuracy, conplecteneas, of lloefulnese of any informacion, apparetus.

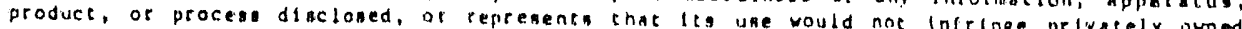

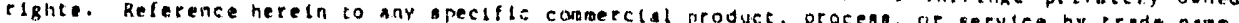

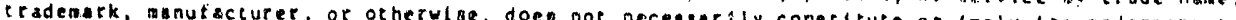
reconondacton, or favoring by the Un ceed recoswendation, or levoring by the Unlted staces Governaent op any agency theteof. The rlew:

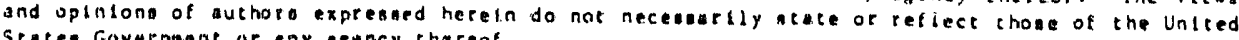
states Governacint or siny agency thereof. 
Task 1. Advanced Core Analysis

Advanced core analysis 1ncludes measurements on the matrix properties of the rock. Matrix properties are linportant even in fractured wells slnce 1t is these properties which determine the rate of gas flow into the fractures.

Cores are belng tested from the fluvlal, coastal, and paludal zones of the Mesaverde. At least two cores from each of these zones from all three wells will be analyzed. Properties measured include permeablitty as a function of confining pressure over the range of 500 to 5000 psi. A minimum of two Klinkenberg permeablitties are being determined from at least five data points. Interpretation includes estimates of pore size from gas slippage. Water adsorption and desorption isotherms will be determined for selected samples with data points beirig obtained at the followling relative humidities: $0,20,40,60,75,90,92,95$ and 98 .

Porosity measurements from both thin section examination and volumetric measurements are belng made. These results will be compared with the porosities of the cored intervals determined from logs.

\section{Prcgress}

Core samples received to date are 11 sted in Table 1 . This table also provides a summary of the analyses performed to date on these samples.

Surface area measurements: Surface areas are being measured using a Quantachrome Monosorb unit on new samples as they are received. In addition, comparisons have been made between the surface areas of whole and crushed samples from the same whole core (Table 2). The crushed samples tend to give somewhat higher surface areas than uncrushed samples, but this is not always the case. Varlations within a single whole core may account for some of the differences observed as shown by the two uncrushed sampies of MWX3 67-35. Results for a single sample are repeatable to within $\pm 0.3 \mathrm{~m}^{2} / \mathrm{gm}$ or better.

Clay analysis: Fluvial zone samples including MWX1 10-13, MWX1 22-20, MWX2 17-22, MWX2 47-34, MWX3 58-14, and MWX3 60-19 have been ground 
and slides of oriented ciay mineral aggregates prepared. These will be used for $x$-ray analysis to determine which clay minerals are present in these samples.

Impregnation of Low Permeability Sandstones: Significant discrepancles have been noted in porosity measurements. In our experience visible porosities from thin section are almost always lower than those measured by rou ne core analyses. ${ }^{1}$ This probably results from inadequate resin impregnation techniques employed by commerctal petrographic labs.

Sandstones from the Multiwell drill holes comnonly range from 2-90 microdarcies permeability. We have found that some standard impregnation procedures result in resin penetration for only a minute distance (sometimes less than $1 \mathrm{~mm}$ ) down from the surface of such low permeability rocks. Thus, thin sections cut at slightly deeper levels may not represent a completely impregnated section.

An Impregnation procedure is now being used which to date has given complete penetration by "Scotchcast" resin for samples having permeability as low as 15 microdarcies. Surface penetration depths of 2-3 mm are attainable for samples in the 2-15 microdarcy $r$ ange and this should be adequate for thin sectioning. The procedure involves injection of a dyed resin into core samples under high pressure. Use of "Scotchcast" resin also requires thit the system be kept at $95^{\circ} \mathrm{C}$ to reduce the resin viscosity to 100 centipoise. However this involves a compromise because Increased temperature which increases the rate of setting of the resin and thus reduces the time avallable for penetration. 
Individual spectmens are evaluated simultaneously along with the resin in a vacuum oven. The sample is then immersed into the resin and a pressure of $1000 \mathrm{psi}$ is applied for 1 to 1.5 hours. Helium is used as the pressurizing gas because of lts low solubility in the resin. The temperature is ralsed to $120^{\circ} \mathrm{C}$ for $2-4$ hours to allow the resin to cure thoroughly. After cooling to room temperature, the sample is ground and polished and then sent to a commercial laboratory for thin sectioning.

This procedure should also give more consistent results for preparation of etched pore casts since the resin penetrates much deeper beneath the surface than previousiy.

\section{Task 2. Flow Along and Across Fractures}

Sometimes production from low permeability gas sands is much higher than could be expected from the properties of the rock matrix as determined by core analysis. The presence of natural fractures is often cited as a key factor in gas production for both fractured and unfractured wells. Vertical fractures have been found in some of the cores recovered in the Multiwel1 project. The cores show that by far the majority of fractures become filled with calcite cement.

As part of this project, flow measurements are being made along and across selected fractured samples as a function of overburden pressure for a minimum of five core samples. Comparative measurements will be made on unfractured nelghboring zones of a given whole core sample. Permeablifty measurements will be made at a minimum of four levels of water saturation for each of at least six samples to assess the effect of water content on permeabilities in fractured systems. The effects of chemical treatments on mineralized fractures will be studied to assess whether such treatments lead to permeabillty enhancement or formation damage.

\section{Progress}

Core samples containing calcite filled fractures have recently been obtained. Planned tests on these samples are listed in Table 3. 
Cores containing fractures were not avallable from several zones of interest. However, some observations on gas flow at high water saturations suggest that low permeablilty sandstone may contaln preferential flow paths other than factures. Preliminary observations have been made on a whole core. A narrow hole was drilled to approximately the center of a whole core sample (about $41 / 2$ " diameter by 3" long) and a plece of stalnless steel cubing was cemented into the hole. The core was submerged in water and nitroger was injected through the stainless steel tube at a pressure of about 30 to $60 \mathrm{ps} \mathcal{L}$. Gas bubbles evolved primarily at freshly cut surfaces but not at surfaces exposed to driling mud. Distribution and size of the bubbles was very inhomogeneous; a few points on the surface continually produced bubbles of much larger size than did the remainder of the surface. With time, additional. points of gas production appeared and flow rates, as indicated by bubble size, Increased at some points. From this qualitative experiment it appears that preferential gas flow paths exist even lia the absence of visible fractures.

A more quantitative measurement of preferential flow has also been tested. Helium is used as the flowing gas and production at different points of the outflow face of a small coce sample is monitored by means of a thermal conductivity detector. By minimizing the size of the sampling tube and mounting it on an $x-y$ positioning stage, the relative amounts of hellum emerglng from the core face can be mapped. Prelimiruary results using a $0.1 \mathrm{~mm}$ stainless steel capillary sensing tube confirm that gas is steadily produced in a few preferential streams. 


\section{Task 3. Chemical A1teration}

Chemical alteration of various mineralogical components and resultant effects on permeability will be investigated. Experiments will include the use of various reagents, including weak acids (e.g. acetic acid), strong acids (e.g. $\mathrm{HClO}_{4}$ ), alkall, and chelating agents (e.g. EDTA). The objective of this work is to determine which features of pore structure determine flow properties and also to explore new possibilities for chemical stimulation of low permeability gas sands.

\section{Progress}

A sunmary of work carried out so far on the effects of chemical treatments is presented in Table 4.

Currently, the fine structure of low permeability gas sands is being investigated through study of the effect of firing on surface areas and adsorption. Table 5 contalns comparisons between several samples from the MWx2 48-9 whole core. Samples were fired for 2 or more hours each at temperatures of $500^{\circ}, 600^{\circ}, 700^{\circ}, 800^{\circ}, 900^{\circ}$, and $1000^{\circ} \mathrm{C}$. Surface area measured by $\mathrm{N}_{2}$ adsorption is highest for the core fired at $600^{\circ} \mathrm{C}$; it then decreases steadily. Accompaning changes in other core properties such as perneability and clay content are also being investigated.

\section{Task 4. Effect of Water on Gas Production}

Water is known to modify greatly the flow of gas ln tight sand and is a key factor in gas production. Permeabllity to gas will be measured at various levels of water saturation established by equilibration of core samples in humidity chambers. Electrical resisitivity at various levels of water saturations and confining pressures will also be measured. Special attention will be given to water distribution within the rock pore space. Circumstances under which water can act to inhibit gas production and the pressure differences necessary to overcome capillary seals formed by water wili also be investigated. Caplllary pressure measurements w111 be made using a high-speed centrifuge. 


\section{Progress}

Relative permeability measurements: Last quarter, relative permeablitiles to gas in the presence of a partial water saturation were reported for four Multiwell samples (MWX3 66-17, MWX3 64-29, MWX3 67-16, and MWX $37-35) .^{2}$ Two levels of confining pressure (500 and 5000 psi) and several water saturations $(0,15,30,45$ and 60 percent) were used in the measurements for each of these samples.

Comparison of these results with those reported previously in the 11terature $e^{3-7}$ requires abstraction of results reported graphically either as permeability or relative permeability on efther linear or logarithmic scales. This has been accomplished and the results are shown in Figure 1 . Open symbols are those obtained at low confining pressures (500 psi and below); filled symbols show data whare confining pressures were in the range of those expected under in situ conditions. Both our data and those in the literature showed lower relative permeabilities generally for measurements under higher confining pressures. A reasonable estinate of the relative permeablifty to gas at high confining pressures is provided by the form of Corey relationship ${ }^{8}$ used by Sampath and Keighin ${ }^{6}$ shown in Figure 1 as a solid line. Suggested means of estinating relative permeablifty to water are also indicated. Detalled discussion is provided in a recently prepared SPE Preprint (13882).9

Capillary pressure measurements: Extensive high-speed centrifuge and desorption data are presented in preprint SPE 13882, to be presented May 21. at the 1985 SPE/DOE Low Perneability Symposium. Detalled comparisons of replicate centrifuge experiments and data analysis methods are lacluded In this paper. 
1. Morrow, N.R., Brower, K.R. and Kilmer, N.H., "Relationship of Pore Structure to Fluid Behavior in Low Permeability Gas Sands," Final. Report; DOE/BC/10216-13 (DE84012721), U.S. Department of Energy, Bartlesville, Sept. 1984.

2. Morrow, N.R., Brower, K.R., Kllmer, K.H. and Ward J.S., "Rock Matrix and Fracture Analysis of Flow in Western Tight Gas Sands," Quarterly Technical Progress Report for DE-AC21-84MC21179, Sept. to Dec. 1984.

3. Byrnes, A.P., Sampath, K. and Randolph, P.L., "Effect of Pressure and Water Saturation on Permeability of Western Tight Sandstones," paper presented at 1979 DOE Symposium on Enhanced O11 \& Gas Recovery and Improved Drilling Technology, Tulsa, Aug. 22-24.

4. Thomas, R.D. and Ward, D.C., "Effect of Overburden Pressure and Water Saturation on Gas Permeability of Tight Sandstone Cores," J. Pet. Tech. (Feb. 1972), 120 .

5. Walls, J.D., Nur, A.M. and Bourbie, T., "Effects of Pressure and Partial Water Saturation on Gas Permeability in Tight Sands: Experimental Results," J. Pet. Tech. (Apr11 1982), 930.

6. Sampath, $K$. and Keighin, C.W., "Factors Affecting Gas Slippage in Tight Sandstones of Cretaceous Age in the Uinta Basin," J. Pet. Tech. (Nov. 1982), 2715 .

7. Walls, J.D., "Measurement of Fluld Salfnity Effects on Tight Gas Sands With a Computer Controlled Permeaneter," paper SPE 11092 presented at. the 1982 Annual Fall Technical Conference and Exhibltion, New Orleans, Sept. 26-29.

8. Corey, A.T., "The Interrelation Between Gas and 011 Relative Permeabilities," Prod. Monthly (Nov. 1954), 38.

9. Ward, J.S. and Morrow, N.R., "Caplllary Pressures and Gas Relative Permeabilities of Low Permeability Sandstone," paper SPE/DOE 13882 presented at 1985 SPE/DOE Low Perneability Symposiun, Denver, May 20-22. 


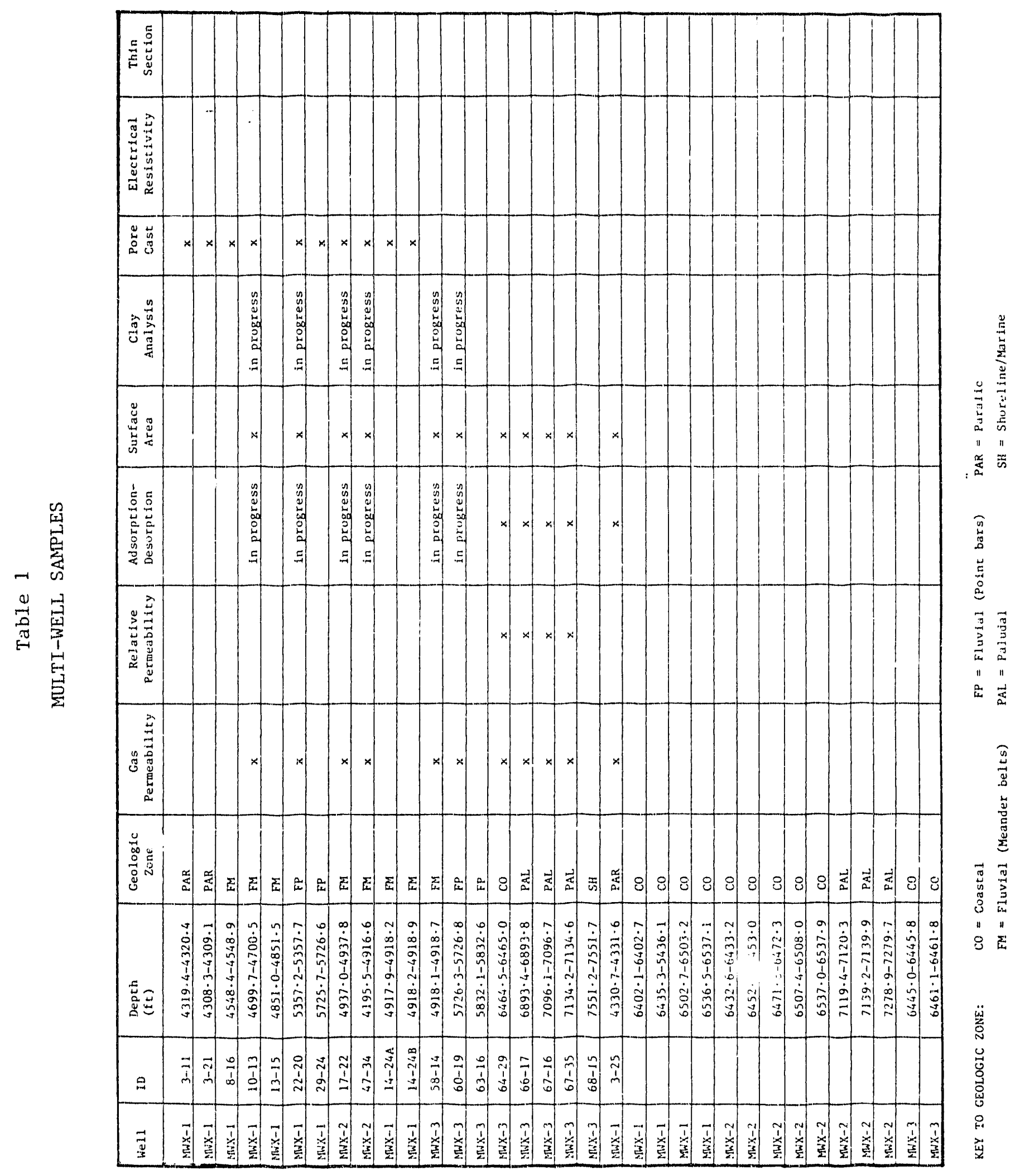


Tabile 2

\section{Surface Area Measurements}

Sample

Designation

MWX1 42-25

MWX2 51-19

MWX3 64-29

MWX3 $66-17$

MWX3 67-16

MWX3 67-35

MWX1 3-25

\begin{tabular}{|c|c|c|}
\hline & BET Surfac & $\left.n^{2} / g\right)$ \\
\hline & Uncrushed & Crushed \\
\hline & & 1.96 \\
\hline & & $2.38 \pm 0.26$ \\
\hline & 3.21 & 4.35 \\
\hline & 1.69 & $2.50 \pm 0.13$ \\
\hline & 3.33 & 3.50 \\
\hline $\begin{array}{l}\text { Sample } 1 \\
\text { Sample } 2\end{array}$ & $\begin{array}{l}3.35 \\
1.66 \pm 0.18\end{array}$ & 3.02 \\
\hline & 1.11 & 1.04 \\
\hline
\end{tabular}

1.96

$\pm 0.26$

3.50

$3.35 \quad 3.02$

$1.11 \quad 1.04$ 


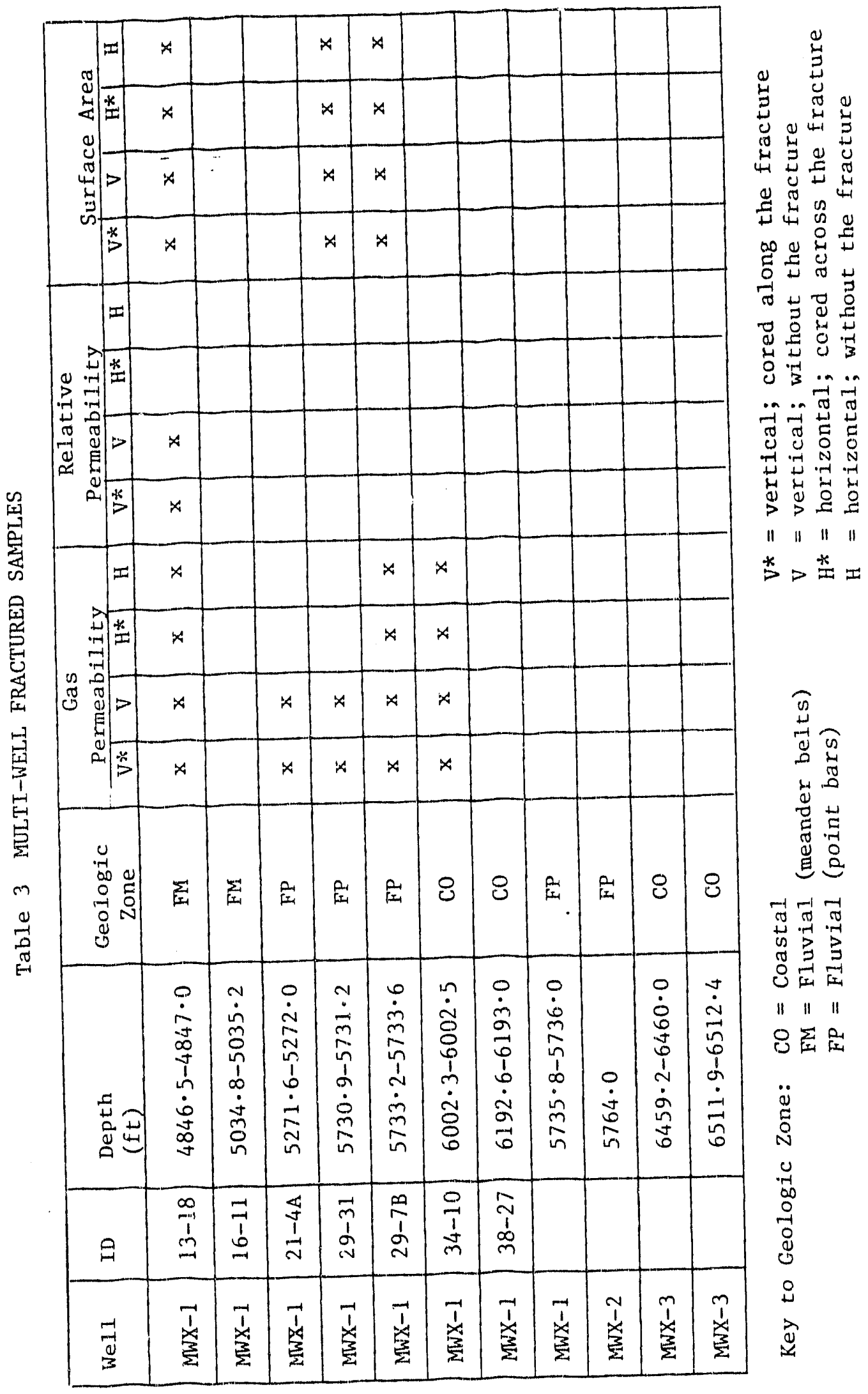




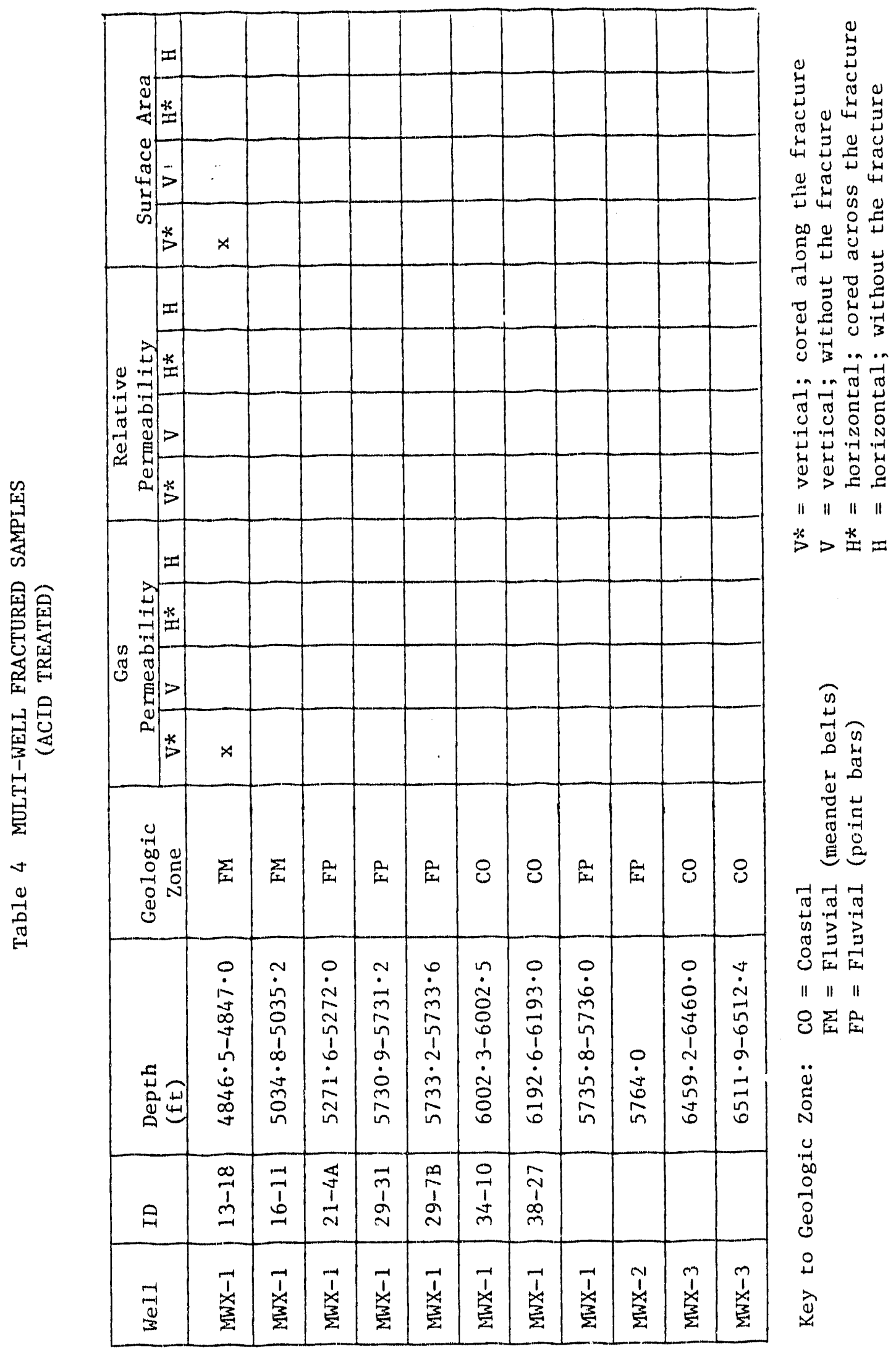


Table 5

BET Surface Areas for MWX2 48-9

Treatment

$$
\begin{aligned}
& \text { none } \\
& 500^{\circ} \mathrm{C} \\
& 600^{\circ} \mathrm{C} \\
& 700^{\circ} \mathrm{C} \\
& 800^{\circ} \mathrm{C} \\
& 900^{\circ} \mathrm{C} \\
& 1000^{\circ} \mathrm{C}
\end{aligned}
$$

Surface Area $\left(m^{2} / g\right)$

1.61

2.85

3.37

2.57

1.62

0.91

0.17 


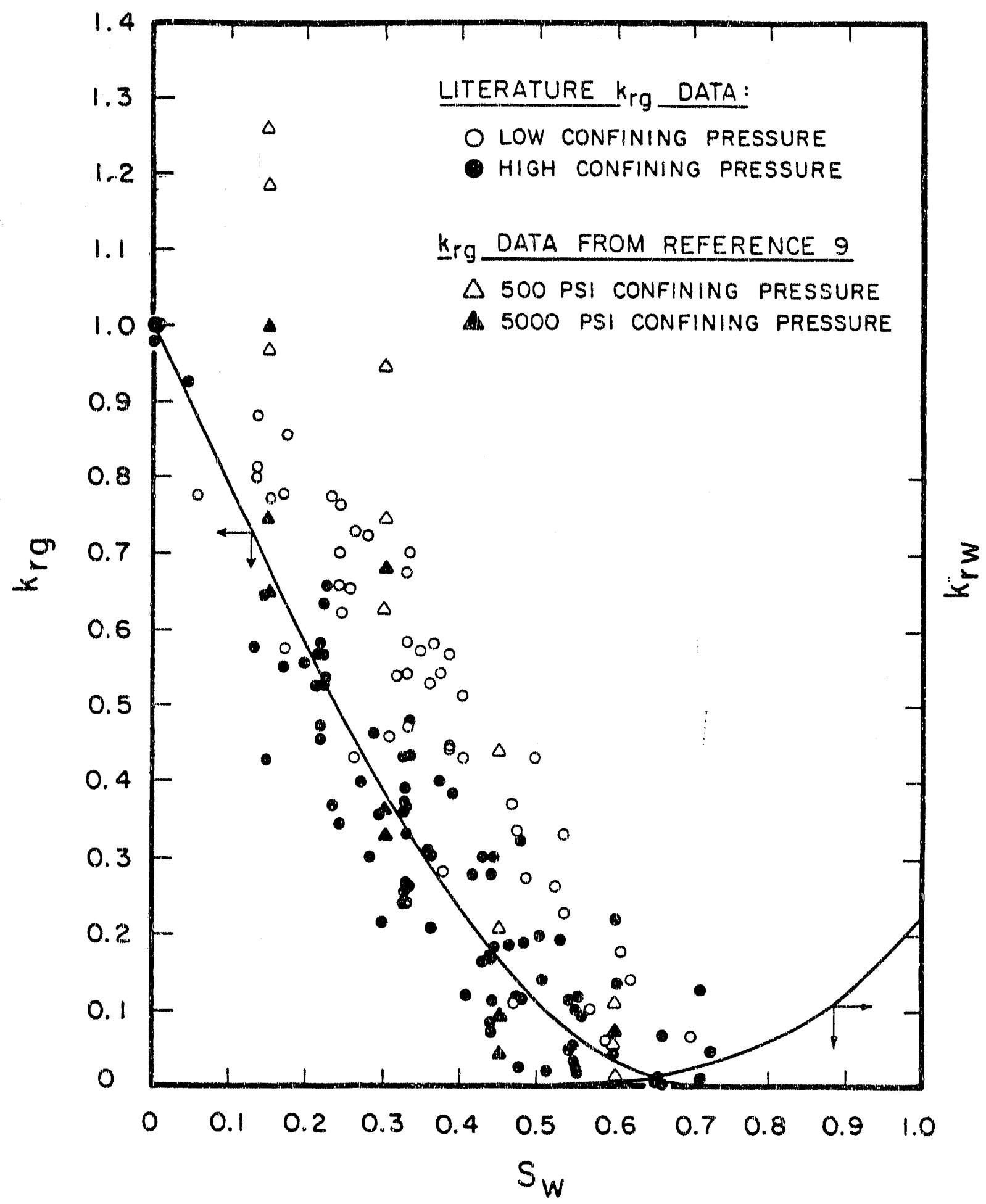

COLLECTED RELATIVE FERMEABILITIES

Figure 1. Gas relative permeability results for tight sandstones and example of estimated relative permeability for the wetting phase. 

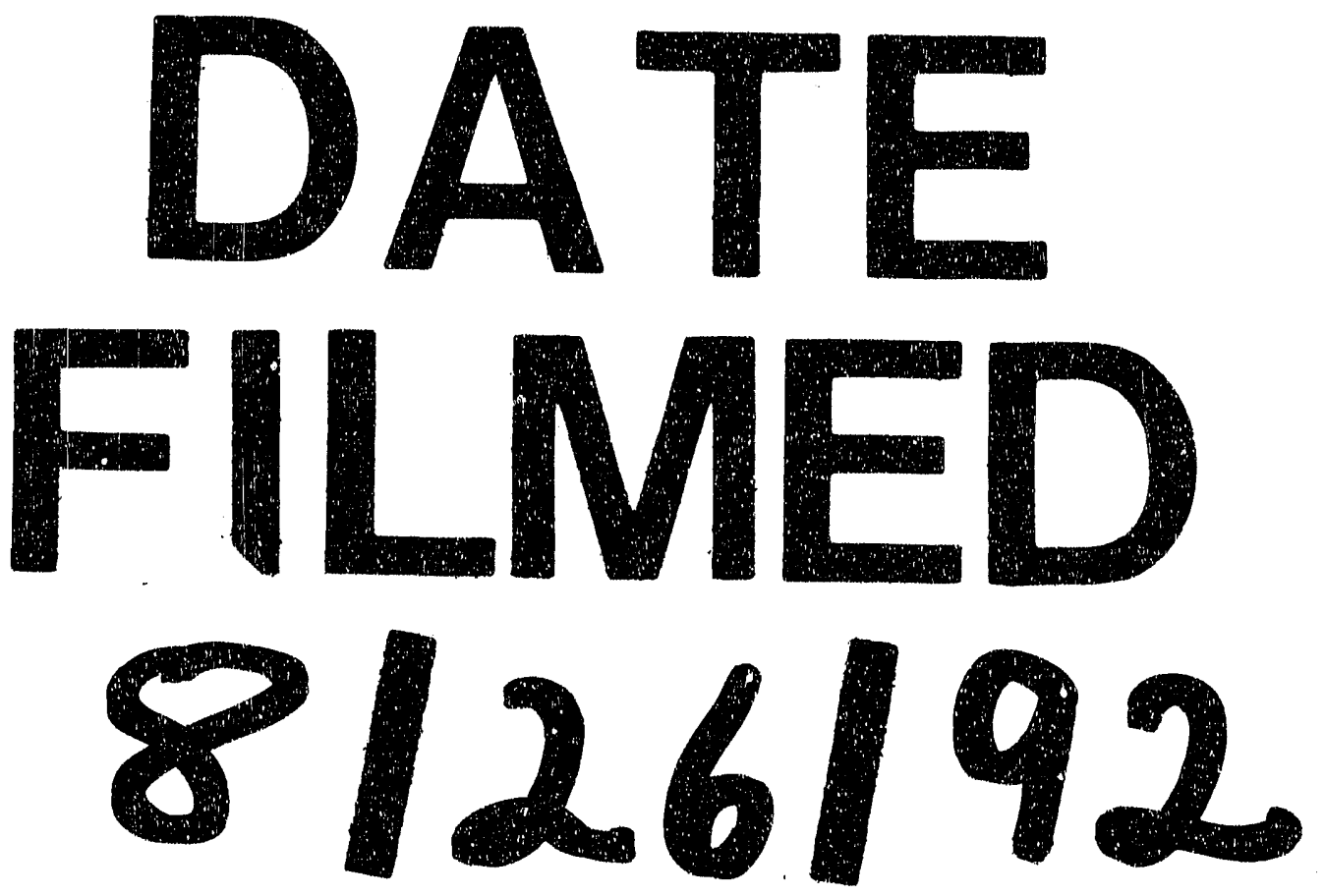

1 
$\exists$ 